How do science teachers teach science - and does it matter?

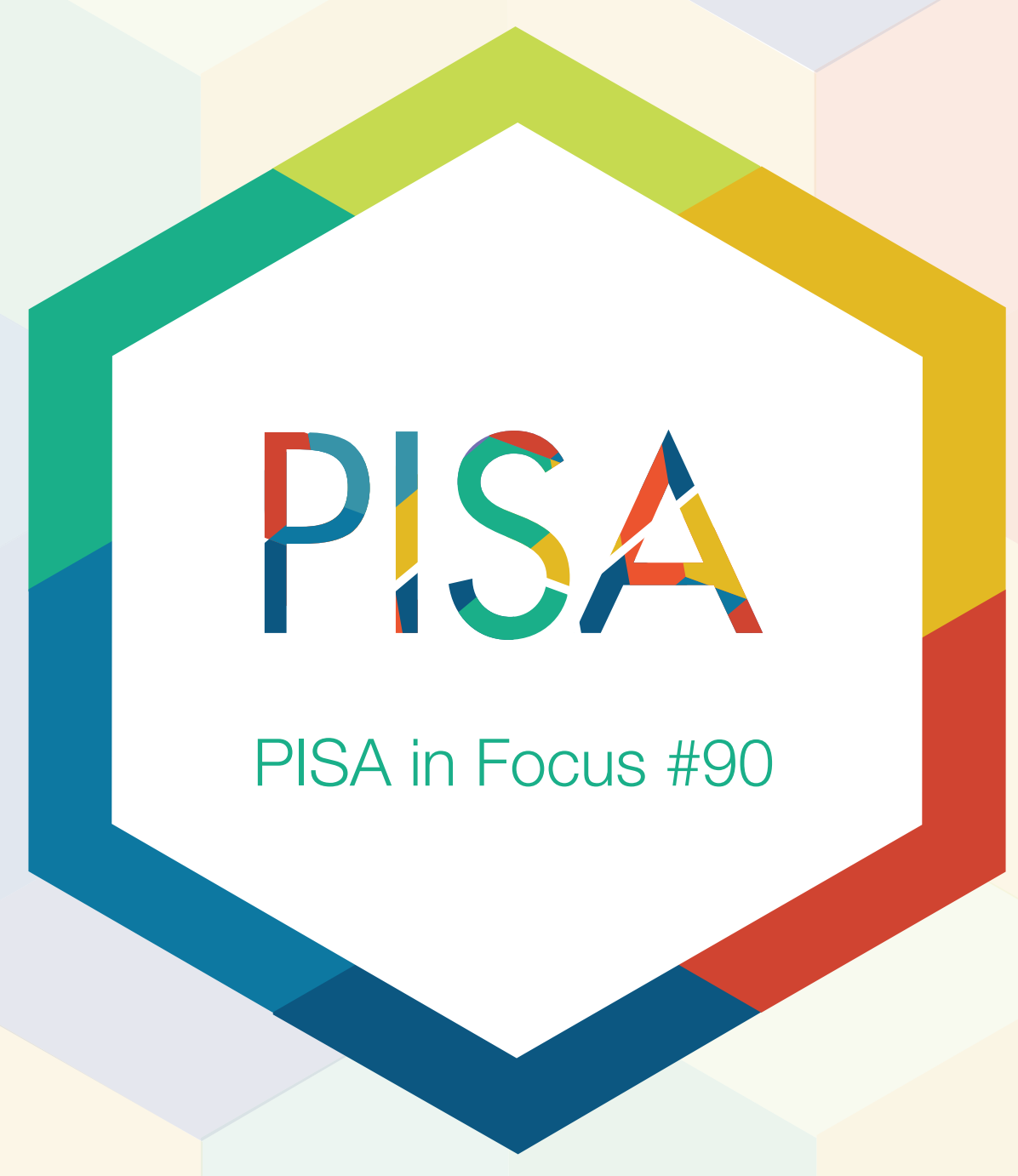






\section{How do science teachers teach science - and does it matter?}

- Enquiry-based science activities are associated with lower test scores in science among students who work in disorderly classrooms or where the teacher has to wait a long time for students to calm down. This negative association is weakened when students work in highly disciplined classrooms.

- Exposure to enquiry-based science activities is associated with more positive attitudes and dispositions towards science among students.

- Teacher-directed instruction is associated with better test scores regardless of the classroom environment.

Much ink has been spilled debating the merits of different science-teaching practices. The debate, anchored in the discussion about the nature of learning, has often sparked emotional reactions on the different sides of the argument. Proponents of enquiry-based science teaching argue that this approach exposes students to the procedures used by professional scientists, while the proponents of traditional practices emphasise the role of teachers in transmitting knowledge about science and in guiding students' learning.

In theory, enquiry-based activities encourage communication and collaboration, and allow students to direct their own learning and develop an authentic interest in a subject. However, these kinds of activities are often more challenging for teachers to lead, as they require both the ability to manage a classroom and an aptitude for improvisation. Students may not gain new knowledge about science if no guidance is provided to them.

In contrast, teacher-directed approaches rely less on teachers' classroom-management skills. They give teachers direct control over how the curriculum content is covered and may be particularly suitable for preparing students for standardised tests. However, students who are solely exposed to teacher-directed instruction tend to be less motivated and have little opportunity to develop collaboration and communication skills.

So what is the best practice to use and is success contingent on the school environment?

PISA 2015 asked students about the teaching practices they are exposed to at school. The analysis of these data reveals interesting findings about the effectiveness of certain teaching practices, particularly enquiry-based science activities and teacher-directed science instruction.

\section{Enquiry-based science activities are associated with better science performance - but not all the time}

The findings emphasise the role of a positive school climate in the success of enquiry-based science activities. Enquiry-based science activities are associated with lower scores in science, especially among students who attend disorderly science classes; but this negative association is weakened when students attend disciplined science lessons. The lack of discipline in a classroom makes it more difficult for teachers to organise enquiry-based activities and, in turn, reduces the effectiveness of this practice.

In almost all countries and economies, students whose science classes are among the least disciplined (i.e. those in the bottom quarter of the index of discipline in science classes) perform worse when exposed to enquiry-based science activities; but in 33 countries and economies, the negative association between these activities and science performance disappears if students attend orderly classes. In particular, in 36 out of 68 countries and economies, students exposed to enquiry-based science activities perform better when they attend classes that are in the top quarter of discipline compared to those who attend classes in the bottom quarter of discipline.

In Thailand, students whose science classes are among the most disciplined (i.e. in the top quarter of the index of discipline in science classes) score slightly higher in science (about 4 points) when they are exposed to enquiry-based activities compared with their peers in the least disciplined classes (i.e. those in the bottom quarter of the index) whose scores drop by an average of 13 points. The benefits of being exposed to enquiry-based activities during a disciplined science lesson (as opposed to during a disorderly lesson) have the greatest impact on performance in Georgia (20 points), Kosovo (15 points), Lebanon (13 points), Malta (14 points) and Slovenia (13 points). 


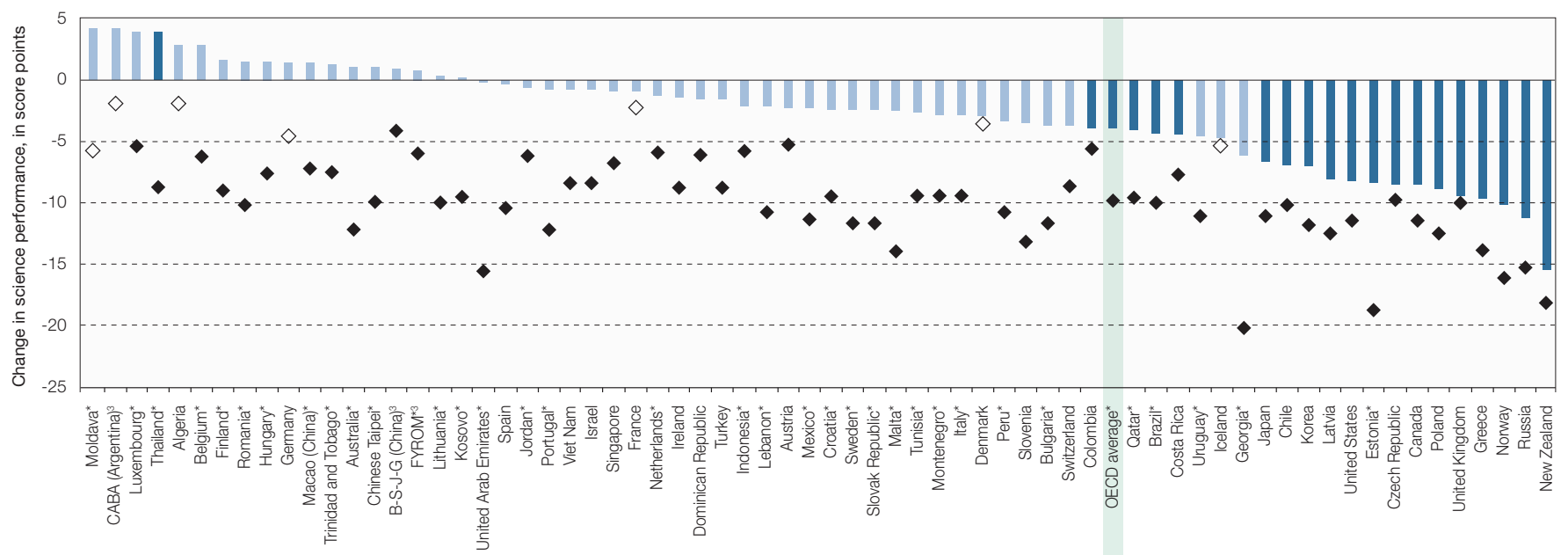

Student characteristics include socio-economic status (as measured by the PISA index of economic, social and cultural status), gender, the number of science courses attended and the grade in which the student is enrolled.

2 School features include any observed and unobserved school characteristics such as funding, practices or policies.

B-S-J-G (China) refers to the four Chinese provinces participating in PISA : Beijing, Shanghai, Jiangsu, Guangdong; CABA (Argentina) refers to the Ciudad Autónoma de Buenos Aires, Argentina; FYROM refers to the Former Yugoslav Republic of Macedonia.

Notes: Statistically significant values are marked in a darker tone.

Statistically significant interactions between the index of enquiry-based science teaching and the top quarter of the index of disciplinary climate in science classes are marked with an asterisk next to the country/economy name.

Countries and economies are ranked in descending order of the change in science performance associated with a one-unit increase in the index of enquiry-based science teaching reported by students, for students in classes in the top quarter of the index of disciplinary climate.

Source: OECD (2016), PISA 2015 Database.

\section{How PISA 2015 measured students' exposure to different teaching practices in science lessons}

PISA 2015 asked students who attended at least one science course that school year to report the frequency with which certain things happened during science lessons. In the analysis, students' answers (on a scale from "never or almost never" to "every lesson") were combined into broad indices of science-teaching practices. The more frequent the exposure to the activities, the higher the value on the indices.

- Enquiry-based science activities aim to engage students in experimentation and hands-on activities, and challenge them to develop a conceptual understanding of scientific ideas. In these practices, the following happens: Students are given opportunities to explain their ideas; Students spend time in the laboratory doing practical experiments; Students are required to argue about science questions; Students are asked to draw conclusions from an experiment they have conducted; The teacher explains how a <school science> idea can be applied to a number of different phenomena (e.g. the movement of objects, substances with similar properties); Students are allowed to design their own experiments; There is a class debate about investigations; The teacher clearly explains the relevance of <broad science> concepts to [the students'] lives.

- Teacher-directed science instruction aims to provide well-structured, clear and informative lessons on a topic. This usually includes teachers' explanations, classroom debates and students' questions. During such instruction, the following happens: The teacher explains scientific ideas; A whole class discussion takes place with the teacher; The teacher discusses [students'] questions; The teacher demonstrates an idea.

- Adaptive instruction in science lessons refers to teachers' flexibility in tailoring lessons to their students' needs, ability and prior knowledge. In such lessons: The teacher adapts the lesson to [his/her] class's needs and knowledge; The teacher provides individual help when a student has difficulties understanding a topic or task; The teacher changes the structure of the lesson on a topic that most students find difficult to understand.

These three strategies are not mutually exclusive; indeed, they are moderately correlated (OECD 2016). As such, they can be combined to achieve the desired learning objectives. 


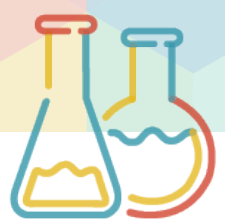

\section{Other approaches to teaching science also have a positive impact on performance - and on students' attitudes towards the subject}

Greater exposure to teacher-directed science instruction is positively associated with science performance in almost all countries, even after accounting for student socio-demographic characteristics, and observed and unobserved school features, such as whether the school is public or private, and how it is funded. This positive association is equally strong in all science sub-domains (such as physical systems, living systems, and earth and space systems), and at all levels of proficiency, and does not vary with student and school characteristics. As such, teacher-directed practices are likely to deliver good results regardless of the classroom environment.

\section{Performance in science and teacher-directed science instruction}

Change in science performance associated with a one-unit increase in the index of teacher-directed science instruction, before and after accounting for student characteristics, and observed and unobserved school features

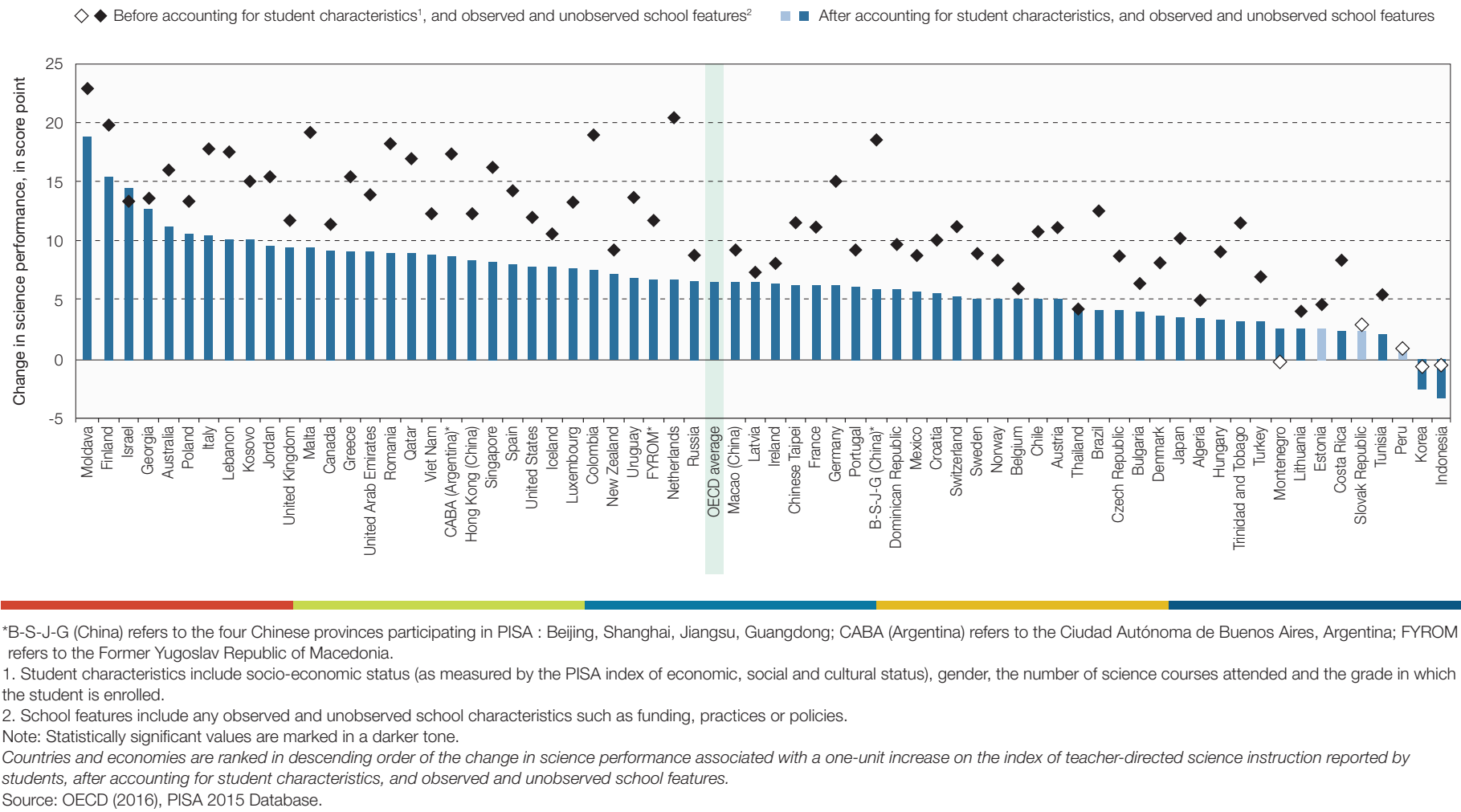

Findings also show that adapting science lessons to students' needs is positively correlated with science performance in the majority of countries, even after accounting for student and school characteristics. This relationship is particularly strong in the Nordic countries, which are known for their comprehensive education systems and for their use of differentiated learning approaches. This positive association does not vary by performance in science sub-domains or by students' levels of proficiency.

Across OECD countries, exposing students to enquiry-based activities seems the most promising approach to nurture positive sciencerelated attitudes, including interest in broad science topics, enjoyment of science, self-confidence in science (known as science self-efficacy) and participation in science-related activities.

The findings also show that, after accounting for science performance, all three teaching practices are positively related to students' expectations of pursuing a career in science - especially enquiry-based practices in the case of girls. 
Performance in science and adaptive teaching in science lessons Change in science performance associated with a one-unit increase in the index of adaptive teaching in science lessons, before and after accounting for student characteristics, and observed and unobserved school features

$\diamond \bullet$ Before accounting for student characteristics', and observed and unobserved school features ${ }^{2} \quad \square$ After accounting for student characteristics, and observed and unobserved school features

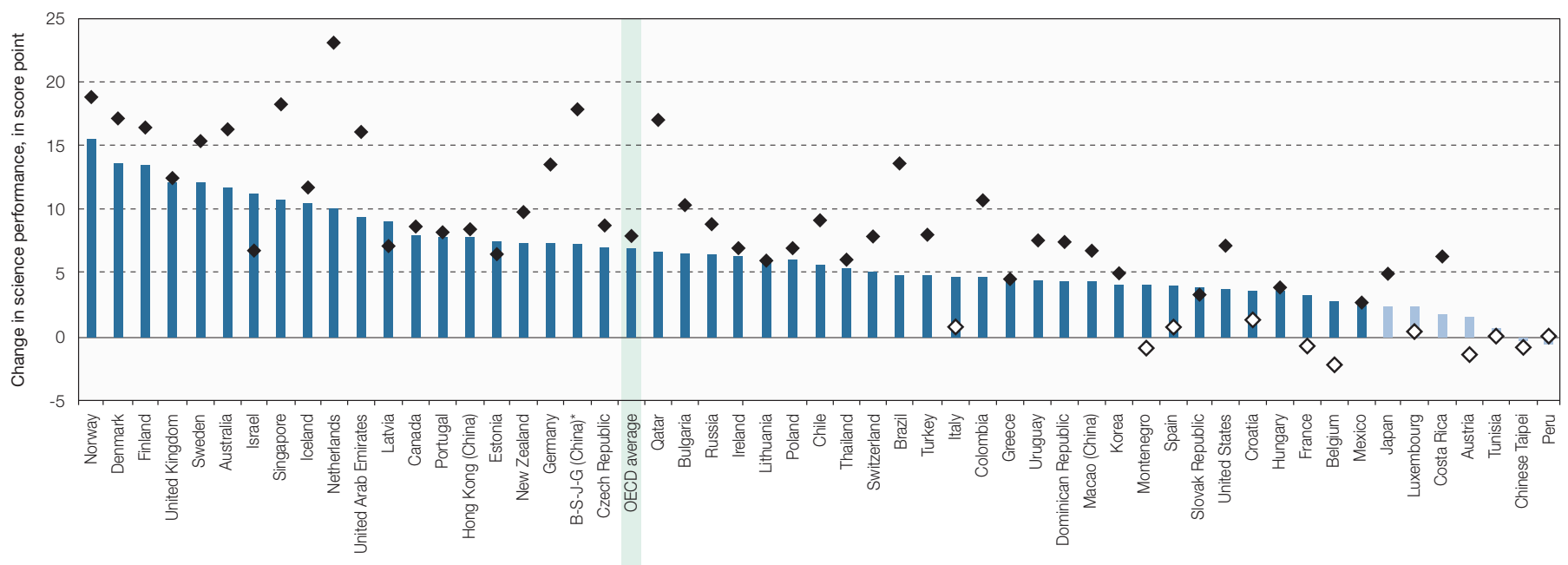

*B-S-J-G (China) refers to the four Chinese provinces participating in PISA: Beijing, Shanghai, Jiangsu, Guangdong.

1. Student characteristics include socio-economic status (as measured by the PISA index of economic, social and cultural status), gender, the number of science courses attended and the grade in which the student is enrolled.

2. School features include any observed and unobserved school characteristics such as funding, practices or policies.

Note: Statistically significant values are marked in a darker tone.

Countries and economies are ranked in descending order of the change in science performance associated with a one-unit increase in the index of adaptive teaching in science lessons reported by

students, after accounting for student characteristics, and observed and unobserved school features.

Source: OECD (2016), PISA 2015 Database.

Teaching practices and science-related attitudes OECD average (34 countries)

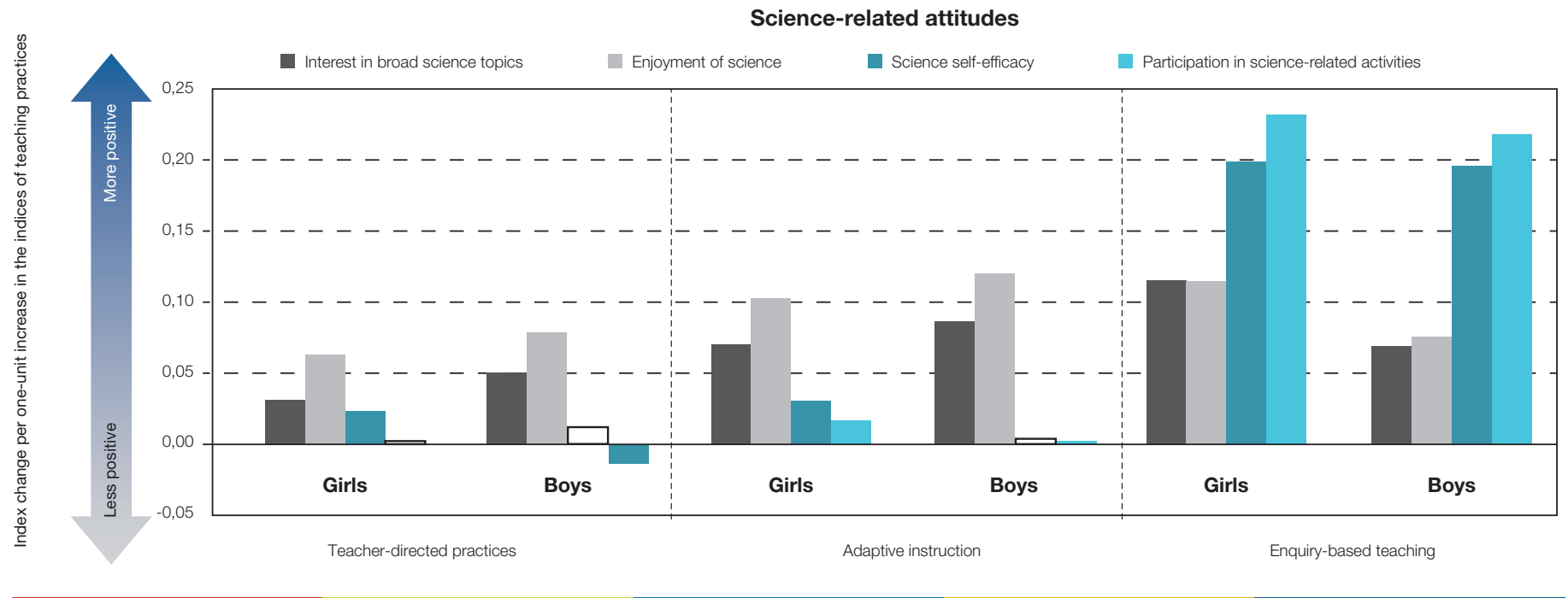

Notes: Results based on linear regression analyses (one for each science-related attitude) accounting for science performance and other teaching practices. Statistically not significant coefficients are marked in white.

Source: OECD (2016), PISA 2015 Database. 




Teaching practices and expectations of pursuing a science-related career OECD average (34 countries)

Girls

Boys

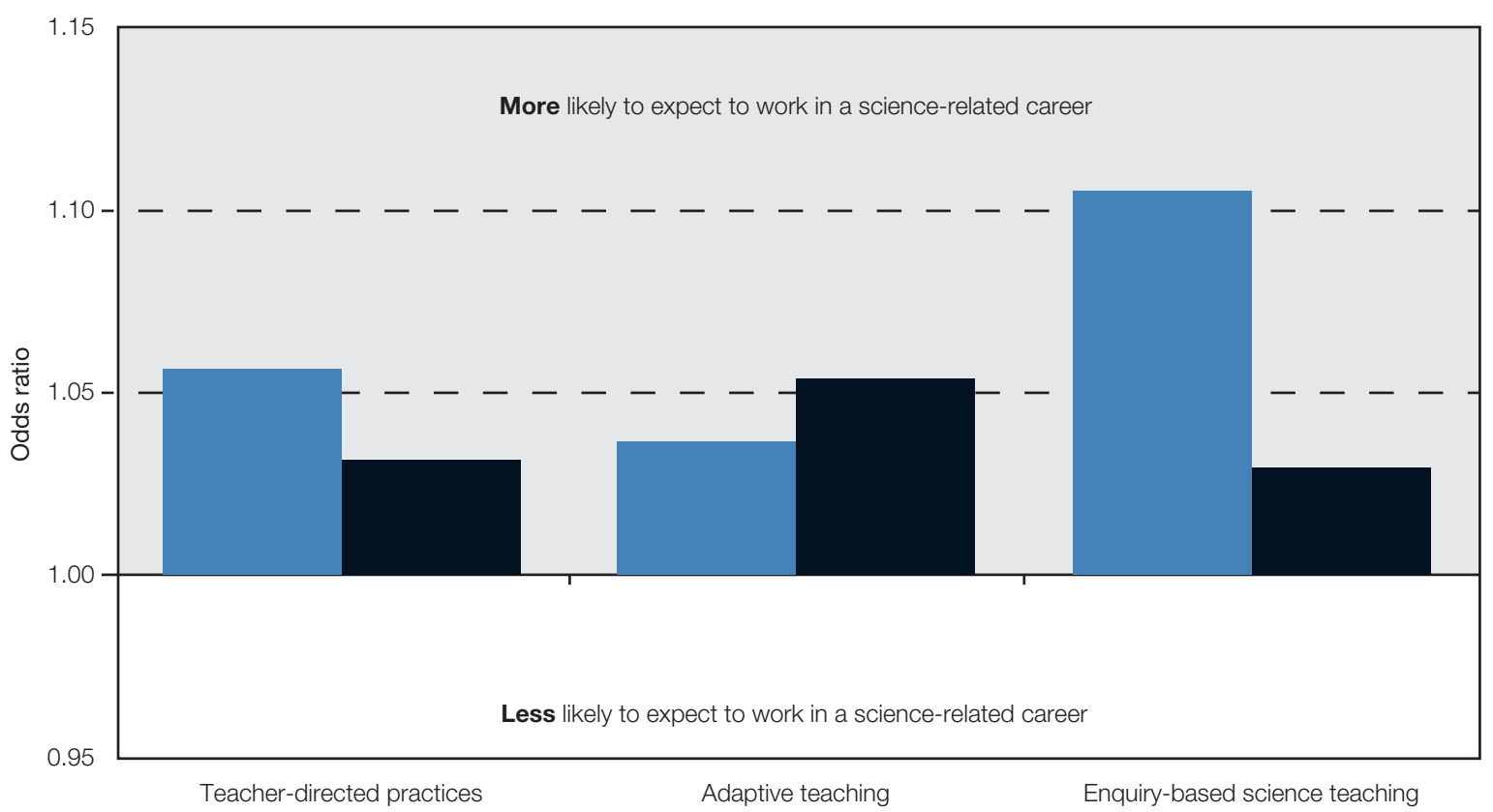

Notes: Results based on logit regression analysis accounting for science performance and other teaching practices.

All results are statistically significant (i.e. statistically different from one).

Source: OECD (2016), PISA 2015 Database.

\section{The bottom line}

Teachers often use a combination of practices to achieve the desired learning outcomes. Empowered with strong classroommanagement skills and professional knowledge, teachers could guide students' learning of science with explicit instruction on basic concepts, then encourage students to participate in enquiry-based activities to consolidate their knowledge.

Adapting science lessons to meet the needs of individual students can benefit those students who struggle to understand a particular concept or topic. Flexibility and responsiveness to their students are the hallmarks of effective teachers. 


\section{For more information}

Contact: Tarek Mostafa (Tarek.Mostafa@oecd.org)

See: Mostafa, T., A. Echazarra and H. Guillou (2018), The science of teaching science: An exploration of science teaching practices in PISA 2015, OECD Education Working Papers Series, No. 188, https://doi.org/10.1787/f5bd9e57-en.

OECD (2016), PISA 2015 Results (Volume II): Policies and Practices for Successful Schools, PISA, OECD Publishing, Paris, https://doi.org/10.1787/9789264267510-en.

Coming next month: What can we learn from PISA about education in developing countries? 
This paper is published under the responsibility of the Secretary-General of the OECD. The opinions expressed and the arguments employed herein do not necessarily reflect the official views of OECD member countries.

This document, as well as any data and map included herein, are without prejudice to the status of or sovereignty over any territory, to the delimitation of international frontiers and boundaries and to the name of any territory, city or area.

The statistical data for Israel are supplied by and under the responsibility of the relevant Israeli authorities. The use of such data by the OECD is without prejudice to the status of the Golan Heights, East Jerusalem and Israeli settlements in the West Bank under the terms of international law.

This work is available under the Creative Commons Attribution-NonCommercial-ShareAlike 3.0 IGO (CC BY-NC-SA 3.0 IGO). For specific information regarding the scope and terms of the licence as well as possible commercial use of this work or the use of PISA data please consult Terms and Conditions on www.oecd.org. 